\title{
Transformation of environmental law in the face of great challenges
}

\author{
Natalia Grigorievna Zhavoronkova', Yuriy Grigorievich Shpakovskiy ${ }^{1}$, Vyacheslav \\ Borisovich Agafonov ${ }^{11}$, and Bulat Umerzhanovich Seitkhozhin ${ }^{2}$ \\ ${ }^{1}$ Kutafin Moscow State Law University, Department of Ecological and Natural Resources Law, \\ Moscow, Russia \\ ${ }^{2}$ Scientific Research Institute of Economic and Legal Researches of Karaganda Economic University, \\ Karaganda, Kazakhstan
}

\begin{abstract}
The purpose of the research is to identify contemporary trends in the transformation of environmental law due to the global and supranational nature of the existing challenges and threats. General scientific methods (dialectical, logical, empirical and prognostic), interdisciplinary (private) methods (system analysis, comparative analysis), as well as special (specific) research methods (comparative legal and formal legal). Based on the research results, the conclusion is formulated, according to which, the specifics of the environmental events, that have occurred, require a radical change in the very paradigm of environmental law, the implementation of a new contemporary environmental policy, the development of environmental standards taking into account the best existing technologies, the transition from the concept of "regulating the negative impact" of economic activities on the environment to a new concept of obtaining "technological advantages due to the use of environmental technologies". The research novelty lies in the fact that for the first time an attempt was made to identify current trends in the transformation of environmental law in the context of exponentially increasing environmental challenges and threats.
\end{abstract}

Keywords: law, environment, ecology, challenges, threats, transformation

\section{Introduction}

The consequences of the COVID-19 pandemic, the largest spill of oil and petroleum products in the Arctic zone of the Russian Federation and other negative events, that occurred in 2020, have shown an awareness of the global nature and vulnerability of the world, as well as the reality and inevitability of impending environmental crises and risks. Therefore, the transformation of environmental law is not only an internal need but also an objective need to adapt to the new realities of life in the contemporary changing world. To what extent environmental law is adapted to such changes and how the transformation takes place is the key question that determines the relevance of this research.

\footnotetext{
${ }^{1}$ Corresponding author: vagafonoff@mail.ru
} 
Currently, increased focus is on transforming law, mainly in the context of the need to overcome the civilisation crisis [1]; at the same time, the problems of transforming environmental law have not yet been reflected in the researches of leading environmental scientists.

The use of the term "transformation" in relation to the law can mean a new phenomenon that does not fit into the definitions of "change", "improvement", "development". For example, the change in the content of law under the influence of digital technologies suggests that the law may be transformed into a different social regulator, possibly into a hardware and software package or some kind of hybrid phenomenon [2]. But the modern "transformation" of law, in our opinion, is the "digitalisation" of law [3], and the international and foreign law implementation of into national legislation [4], and even a deep, sharp and fundamental transformation of environmental law in the institution of survival, a change in the type and form of law.

Currently, the Russian legal science is actively developing, it is in demand and is in no way inferior to its foreign counterparts [5]; therefore, the improvement of environmental legislation is one of the priority areas of the modern state environmental policy and fundamental science of environmental law [6].

But is there any fundamental transformation of the content, a change in the type and/or form of environmental law? If yes, then in what areas, how, and what impact does the possible transformation of environmental law have on the area of environmental legal regulation? That is the main question, the answer to which is the purpose of this research.

\section{Methods}

General scientific methods (dialectical, logical, empirical, prognostic), interdisciplinary (private) methods (system analysis, comparative analysis), as well as special (specific) research methods (comparative legal, formal legal) were used as scientific and cognitive tools and techniques in the study.

\section{$3 \quad$ Results}

It is common to find terms reflecting the position of environmental law in the context of areas of possible transformation (in the current decade) as follows, "environmental policy", "challenges", "threats", "technologies", "global changes", "environmental technologies", "environmental regulation" and "best available technologies".

Outside of the points of view and reliability of assessments, it can be safely stated that experts, politicians and inhabitants in all countries agree on one thing, the world is on the verge of global environmental changes (transformations) [7]. But if there are radical changes in politics, economics, technology and all areas of life, then how can they not affect the law, particularly in a radical dimension? In other words, the transformation of environmental law is not only an internal need but also an objective need to adapt to the new realities of life in an unknown world.

In what way can (or should) the radicalisation of the environmental component of "sustainable development" manifest itself, which will require the transformation of environmental law? Or, in other words, what events and problems will require a sufficiently radical change in the paradigm of environmental law?

The list of events (problems) can be endless and their classification (selection) is rather arbitrary; nevertheless, we will single out four key global and internal "challenges":

- globalisation of environmental problems, such as climate, biodiversity, desertification, lack of water resources, pollution and waste; 
- promotion of synthetic biology, bioengineering, food industry, lifestyle and recreation;

- promotion of alternative energy, changes in mining and waste disposal (recycling) technologies;

- digitalisation, robotisation and the emergence of artificial intelligence.

The list of "challenges", as well as the list of "goals" of environmental development and environmental safety, can be short, extensive, stable and changing, but no one will dispute their existence, importance, urgency and impact on the economy, ecology, politics and law [8].

The underlying idea behind the transformation of environmental law is the transition from the concept of "regulation of the negative impact" of economic activities on the environment to the concept of technological advantages, environmental technologies and a "green" economy. Law, including environmental law, cannot be "transformed" at once by abolishing old standards and introducing new ones. The transformation of environmental law is a long and gradual process of change. The complexity of the transformation of environmental law stems from many features and characteristics, for example, in the fact that environmental standards are contained in almost all branches of law (and constitute, although formally not codified but essentially close to this set of environmentally oriented laws and rules.

Transformation in the environmental law affects not only the entire legal system but also requires certain changes in the information (environmental monitoring) and technical rate setting, standardisation, technology regulation, spatial development, economic and energy policies, as well as the entire system of environmental legal relations.

\section{Discussion}

But why did such a formulation of the problem arise? What is the point of even introducing terms that are not well-established, not obvious, and not practical? What is the benefit/harm for the law in the recognition or non-recognition of the very fact of "transformation of law"? In the opinion of many experts, there are hundreds of problems in environmental law that are more relevant and more urgent; so the discussion about the "transformation" of environmental law, or its "diffusion" is not so relevant [9].

Law does not exist by itself, it is a part of politics, economics, management and culture, it "exists in the form of institutions and ideas about institutions" $[10,11]$. On the one hand, law is a "distorted reflection of reality" [12]; on the other hand, law changes (at least streamlines) the reality and is involved in shaping the future. For politics, economics and management, law is an understandable and accessible language, tool, form and method of responding to external changes (circumstances).

But if we take the time of deep transformation in the economy, politics, ecology, technology and international relations as a fact, then it is logical to admit that environmental law also needs adequate changes, that is an equally profound transformation [13].

Why is it important to study the phenomenon of legal "transformation" in environmental law? Environmental law is largely international, both globally and locally, legal environmental standards are very often transformed from natural laws (for example, scientists have long proven that the fundamental right to life fully relates to environmental law) [14], possible disasters, emergencies and crises are also very often of a natural type and are regulated by the provisions of environmental law [15], and the complexity of certain branches of law leads to the fact that many of their provisions have a special specific dual treatment [16].

There are many convincing examples of the close connection between environmental law and the key development trends; but something else is important, i.e. the published 
statistical data on the state of the environment and individual components in our country and in the world [17] testify to serious shortcomings in the environmental policy implementation [9].

The environmental conditions are also complicated by the fact that the role and scale of the legal environment, in general, the legal impact on society, are changing. The subject of legal regulation is becoming almost unlimited, as a result, the lack of relevant and effective regulators has become keenly felt in all areas of innovative public relations [18].

\section{Conclusion}

In summing up the research outcomes, we can formulate the conclusions and proposals as follows:

1. Transformation of the environmental law is an objective, complex and contradictory process of changing legislation due to the influence of international legal standards (implementation) and fundamental changes in the quality of the environment, biodiversity, climate, economics, politics, technology and consumer characteristics.

2. Transformation of the environmental law, in contrast to "modernisation" and "improvement" presupposes, albeit a consistent, but to a greater extent a radical change affecting not only the forms and types of legal regulation but also determining changes in the economy, politics, technology and even lifestyle.

3. Transformation of the environmental law is part of the globalisation process and the competitive advantages of states that have chosen an environmental economy. Transformation of the environmental law is meaningless without changing the development paradigm from "consumer-focused" to "environmental-economic". The areas, types, methods and results of transformation are not always obvious and categorical but the general trend is quite clear and oriented towards the globalisation of environmental standards and rules, the "technologisation" of the environmental law, and the creation of prerequisites for a full-fledged environmental economy of sustainable development.

4. Transformation of the environmental law is multidirectional, on the one hand, it occurs under the influence of external factors, on the other hand, it itself is a catalyst for many changes in the environmental policy.

5. Transformation of the environmental law (goals, objectives, means and areas) should be enshrined as a principle and trend in various strategic planning documents and national projects.

The article was written within the framework of the state assignment 075-00293-20-02 of 05/25/2020

"Transformation of the Russian Law in the Face of Great Challenges: Theoretical and Applied Foundations. Topic number - FSMW2020-0030".

\section{References}

1. A.N. Savenkov, State and Law during the Crisis of Modern Civilisation (Prospect, Moscow, 2020)

2. T.Ya. Khabrieva, Projections of Modern Transformations of Law in the Legal Doctrine and Practice. Accessed on: June 23, 2021. [Online]. Available: https://izak.ru/img_content/125-kfu.pdf

3. V.N. Sinyukov, Lex Russica (Rus. Law), 1(9), 9-18 (2019). https://doi.org/10.17803/1729-5920.2019.154.9.009-018

4. I.R. Mustafin, Legal State: Theory and Pract. 3(53), 172-176 (2018) 
5. A.N. Savenkov, State and Law during the Crisis of Modern Civilisation (Prospect, Moscow, 2020)

6. S.A. Bogolyubov, Actual Problems of the Environmental Law (Yurayt Publishing House, Moscow, 2018)

7. T. Wiedmann, M. Lenzen, L.T. Keyßer, J.K. Steinberger, Nat. Commun. 11, 3107 (2020). https://doi.org/10.1038/s41467-020-16941-y

8. G.V. Zhavoronkova, G.V. Vypkhanova, Lex Russica (Rus. Law), 1(158), 28-42 (2020). https://doi.org/10.17803 / 1729-5920.2020.158.1.028-042

9. N.G. Zhavoronkova, Yu.G. Shpakovsky, Lex Russica (Rus. Law), 10, 53-62 (2019). https://doi.org/10.17803/1729-5920.2019.155.10.053-062

10. Yu.A. Vedeneev, State and Law, 1, 7-19 (2020). https://doi.org/10.31857/S013207690008397-8

11. Yu.A. Vedeneev, State and Law, 2, 7-24 (2020). https://doi.org/10.31857 / S013207690008346-2

12. G.A. Gadzhiev, Ontology of Law: (Critical Study of the Legal Concept of Reality) (Norma: INFRA-M, Moscow, 2013)

13. O.L. Dubovik, Proc. Inst. State and Law Rus. Acad. Sci. 2, 7-37 (2010)

14. V.I. Evtushenko, E.A. Kravtsova, Hist. State and Law, 15, 2-3 (2008)

15. V.B. Agafonov, N.G. Zhavoronkova, S.G. Kharchenko, Ecol. Indus. Russia 24(7), 68-71 (2020). https://doi.org/10.18412 / 1816-0395-2020-7-68-71

16. S.S. Alekseev, The Structure of the Soviet Law (Moscow, 1975)

17. W.J. Ripple, C. Wolf, T.M. Newsome, P. Barnard, W.R. Moomaw, Biosci. 70(1), 100 (2020). https://doi.org/10.1093/biosci/biz088

18. V.N. Sinyukov, Lex Rus. (Rus. Law), 74(2), 9-20 (2021). https://doi.org/10.17803/1729-5920.2021.171.2.009-020 